\title{
ENSINO DE HISTÓRIA E PENSAMENTO DECOLONIAL EM PROCESSOS DE IDENTIFICAÇÃO QUILOMBOLA
}

\author{
TEACHING HISTORY AND DECOLONIAL THINKING IN QUILOMBOLA \\ IDENTIFICATION PROCESSES
}
ENSEÑANZA DE HISTORIA Y PENSAMIENTO DECOLONIAL EN PROCESOS DE IDENTIFICACIÓN QUILOMBOLA

Marizete Lucini

malucini@hotmail.com

Andréia Teixeira dos Santos
deia.teixeira.s@gmail.com

\begin{abstract}
REVISTA PEDAGÓGICA
Revista do Programa de Pós-graduação em Educação da Unochapecó | ISSN 1984-1566

Universidade Comunitária da Região de Chapecó | Chapecó-SC, Brasil

Como referenciar este artigo: LUCINI, M.; SANTOS, A. T. Ensino de história e pensamento decolonial em processos de identificação quilombola. Revista Pedagógica, Chapecó, v. 20, n. 45, p. 36-52, set./dez. DOI: http://dx.doi.org/10.22196/rp.v20i45.4490
\end{abstract}

RESUMO: Este artigo propõe refletir sobre o Ensino de História e o pensamento decolonial na análise de processos de identificação étnico-racial em comunidades quilombolas, aqui compreendidos como espaços políticos de resistência às práticas sociais colonizadoras da memória ancestral. A discussão origina-se de pesquisa com abordagem qualitativa, do tipo estudo de caso, em desenvolvimento na Escola Estadual Quilombola Gilberto Amado, sobre os processos de identificação quilombola em comunidade remanescente de quilombo urbano Porto D'Areia - Estância/Sergipe. O aporte teórico ancora-se no pensamento decolonial ao questionar todas as formas de colonização do saber, do poder e do ser. Espera-se contribuir para a superação do olhar colonizador que inferioriza o negro e interfere no processo de reconhecimento da identidade quilombola.

Palavras-chave: Ensino de História. Pensamento Decolonial. Educação Quilombola. Educação Escolar Quilombola. Interculturalidade.
ABSTRACT: This present article proposes a reflection on History Teaching and the decolonial thinking through the analysis of the ethnic-racial identification processes in Quilombola communities, understood here as political spaces of resistance to colonizing social practices of ancestral memories. The discussion is based on a qualitative approach research, a case-study type, developing at Escola Estadual Quilombola Gilberto Amado, about the quilombola identification processes in the remaining urban quilombo community Porto D'Areia - Estância/Sergipe. The theoretical contribution is based

on the decolonial thinking, by inquiring colonialism and all its forms of knowledge, power and being. Hence, we hope to contribute to the overcoming of the colonializing point of view that diminishes the black people and interferes in the process of recognition of a quilombola identity.

Keywords: History Teaching. Decolonial Thinking. Quilombola Education. Quilombola School Education. Intercultural

RESUMÉN: Este artículo propone reflejar sobre la Enseñanza de Historia y el pensamiento decolonial en el análisis de procesos de identificación étnico-racial en comunidades quilombolas, aquí comprendidos como espacios políticos de resistencia a las prácticas sociales colonizadoras de la memoria ancestral. La discusión se origina de investigación con abordaje cualitativo, del tipo estudio de caso, en desarrollo en la Escuela Estadual Quilombola Gilberto Amado, sobre los procesos de identificación quilombola en comunidad remanente de quilombo urbano Porto D'Areia - Estancia / Sergipe. El aporte teórico se ancla en el pensamiento decolonial al cuestionar todas las formas de colonización del saber, del poder y del ser. Se espera contribuir a la superación de la mirada colonizadora que baja el negro e interfiere en el proceso de reconocimiento de la identidad quilombola.

Palabras clave: Enseñanza de Historia. Pensamiento Decolonial. Educación Quilombola. Educación Escolar Quilombola. Interculturalidad. 
Este artigo resulta de reflexões relativas ao Ensino de História e ao pensamento decolonial em processos de identificação quilombola realizadas a partir de pesquisa desenvolvida em nível de mestrado que objetivou compreender o processo de constituição da identidade quilombola da comunidade remanescente de quilombo Porto D'Areia - Estância/Sergipe, por meio de um projeto de pesquisa com alunos do Ensino de História dos Anos Finais do Ensino Fundamental da Escola Estadual Quilombola Gilberto Amado, localizada na comunidade remanescente de quilombo Porto D’Areia, Estância-Sergipe. Neste texto apresentaremos algumas reflexões sobre os processos de identificação quilombola em contexto colonizado pelo pensamento eurocentrado, por compreendermos que a constituição de processos de identificação se estrutura nas relações sociais que se estabelecem entre os sujeitos e as coletividades que os circundam.

A identidade quilombola, de acordo com Gomes (1995) é uma identidade coletiva que é evocada por um grupo que busca reivindicar uma maior visibilidade social diante do silenciamento ou situação de opressão a que o grupo foi historicamente submetido. Para Bastos (2009), a construção dessa categoria social mostra as similitudes existentes na comunidade bem como a sua diferenciação entre ela e outras sendo, a autoconstrução da identidade quilombola uma expressão da mobilização política dos sujeitos autodeclarados quilombolas, como um importante instrumento de luta e organização social.

Em outra publicação, uma das autoras, ao discutir a questão da identidade no âmbito dos movimentos sociais, afirmava em relação a outro campo de pesquisa com movimentos sociais, a partir de Castells (2006) que há:

[...] basicamente três tipos de identidades presentes nas ações dos sujeitos pesquisados [...]. A primeira apontada é a Identidade $L e-$ gitimadora, cuja origem está nas instituições dominantes que expandem e racionalizam sua dominação; a segunda é a Identidade de Resistência, em que os atores em condições de desvalorização estigmatizados constroem resistência; a terceira é a Identidade de Projeto, em que os atores constroem uma nova identidade, capaz de redefinir sua posição na sociedade (LUCINI, 2007, p. 67-68).

Ao nos remetermos ao contexto em questão, importa pensarmos que os sujeitos quilombolas, ao se reconhecerem e serem reconhecidos como sujeitos sociais com direitos conquistados, vivenciam situações de empoderamento que perpassa a constituição de uma identificação que os ancore na perspectiva de resistir como coletivo às situações de discriminação. Como indica Bastos, os sujeitos sociais,

Na medida em que vivenciam situações de discriminação demonstram sua auto-identi- 
1 A lei 10.639/2003 alterou a Lei de Diretrizes e Bases da Educação Nacional, instituindo a obrigatoriedade do Ensino História e Cultura Afro-Brasileira e Africana na Educação Básica. ficação que aparece como uma identidade de resistência, segundo a tipologia de Castells (1999). Indivíduos pertencentes a grupos desvalorizados socialmente recorrem a este tipo de referência como forma de resistência aos estigmas impostos. (...) A partir do momento em que sujeitos submetidos à lógica de dominação criam identidades capazes de reorganizar a forma em que se inserem na sociedade, tem-se uma identidade de projeto. Ambas estão relacionadas ao combate ao preconceito, ao sexismo e ao racismo. (BASTOS, 2009, p. 50)

Nesse sentido, compartilhamos com o raciocínio de Bastos (2009) quando, ao analisar os diversos espaços em que a identidade de um indivíduo se constitui, afirma que a escola é um espaço privilegiado de formação onde não se pode deixar de trabalhar as relações étnico-raciais e sua reestruturação na atualidade. A discriminação pode estar presente na escola por meio de ações explícitas e implícitas, desde discursos abertos, passando pela ausência de referenciais negros nos programas de disciplinas e pelo menosprezo às manifestações africanas e afro-brasileiras. Apesar da existência de dispositivos como a Lei 10.639 de $2003^{1}$, a temática da Educação das Relações Étnico-Raciais é pouco abordada nas escolas, bem como no campo do Ensino de História.

Ao observarmos a história do ensino de História, podemos afirmar que ele contribuiu e ainda contribui para a difusão de uma visão negativa do negro ao privilegiar narrativas que silenciam sobre a História da África e dos Afro-brasileiros, bem como sobre suas histórias de resistência. Silenciamento que está presente em livros didáticos e na postura de alguns professores e escolas que acabam reforçando estereótipos que inferiorizam o negro e sua cultura, seja na forma de exposição de conteúdos baseados nas narrativas produzidas pelo colonizador, seja na omissão no que se refere à divulgação da trajetória do negro para além da escravidão.

Na perspectiva de abordagem de uma história que silencia sobre o negro após a abolição da escravatura no Brasil, os negros praticamente desaparecem dos livros didáticos no que se refere aos aspectos sociais, econômicos, culturais e políticos do país. Assim como "desaparece" o negro, também desaparecem os quilombos e suas novas configurações ao longo do tempo, contribuindo para reforçar estereótipos negativos que provocam a negação e/ou o silenciamento sobre a identificação quilombola.

Nesse sentido, é preciso romper com os padrões eurocentrados ainda presentes em nossos materiais didáticos, e assumir uma postura decolonial, que valorize nossa ancestralidade, nossos saberes e fazeres. Como afirmamos em outra publicação, a identidade encontra na história e na memória sua sustentação, sendo, por isso, importante que, no ensino de História se ressalte a trajetória de luta 
de um grupo marginalizado como os negros, expondo-a de forma positiva, a fim de que um processo de identificação se inicie.

A identificação quilombola é constituída, de maneira geral, por vários sujeitos, e pela constante interação entre o que é vivido com o que é aprendido, o que denota a importância da escola nesse processo de formação. Como indica Souza (2009), a construção da identificação quilombola ocorre em diferentes espaços e tempos de ensino e aprendizagem, dentro e fora da escola, sendo constituída nas relações que ocorrem no âmbito familiar, nos grupos culturais, nos movimentos sociais e na educação escolar. Para que essa identificação seja possível, é preciso conhecimento acerca da origem do grupo, e isso perpassa a educação (formal e informal). No caso da educação formal, Silva (2009) afirma que:

A educação escolar corrobora e participa no processo de construção das identidades, quando estabelece um diálogo com outros espaços culturais, com objetivo de valorizá-los e usá-los para aquisição de conhecimentos, tudo isso por meio de outras linguagens e estratégias. A aproximação dos alunos quilombolas da escola e de um ensino que valorize suas experiências e de seus antepassados, permitirá erigir as bases de uma formação cidadã. (SILVA, 2009, p. 4)

Em relação à educação não-formal para a constituição de uma identidade, Moura (2006) nos alerta para o desenvolvimento do chamado currículo invisível, aquele que destaca os valores, os princípios de conduta e as normas de convívio de um grupo que permite e promove ou não uma afirmação positiva da identidade dos membros de um grupo social. No caso de uma comunidade quilombola, permitiria o entendimento da necessidade de atualização do conceito de quilombo, desvinculando-o do quilombo colonial. Essa desvinculação implica conhecimentos do processo histórico vivenciado, bem como necessita que se trabalhe com as memórias de resistência dos ancestrais em relação ao processo de escravização.

Nesse movimento necessário de reconhecimento da participação negra na história, a certificação das comunidades quilombolas é um direito que, ao ser conquistado, atua também como um dispositivo que contribui nesse processo de identificação. Simas (2012) afirma que, a partir do momento em que são certificadas, nas comunidades quilombolas surge uma nova identidade voltada para a aquisição de direitos. $\mathrm{O}$ autor se refere assim ao surgimento dos quilombolas como sujeitos políticos que lutam de forma organizada. Para Souza (2009, p. 44):

Ao serem reconhecidas como remanescentes de quilombo, as comunidades rurais negras existentes se apoderam de um nome que traz 
2 Para maiores esclarecimentos sobre o movimento negro, recomendamos a leitura do texto DOMINGUES, Petrônio. Movimento negro brasileiro: alguns apontamentos históricos. Tempo, Niterói, v. 12, n. 23, 2007, p. 100 -122, bem como a obra de GOMES, Nilma Lino. O Movimento Negro educador: saberes construídos nas lutas por emancipação. Petrópolis, RJ: Vozes, 2017. consigo uma série de desafios para a memória dos grupos, que precisam desconstruir as noções negativas que permeiam o termo quilombo e compreender seu novo sentido em prol da luta pela terra. Os desafios à memória das comunidades impõem aos seus membros um 'trabalho da memória' (BOSI, 1994), em que lembranças doloridas e referidas ao tempo das amarguras da escravidão são trazidas para o presente em razão da luta maior por uma terra e um lugar próprio.

O trabalho de memória das comunidades remanescentes de quilombo envolve o lembrar de fatos e personagens que são ressignificados no presente, o que é um trabalho educativo que serve como referencial para que se ensine e aprenda quem se é e qual o sentido de ser quilombola.

Além das memórias de resistência, rememorar as formas de vida constituídas nos quilombos também se constitui numa necessidade, pois é uma alternativa possível de afirmação da cultura e uma necessidade para que se desconstrua a ideia de quilombo como sinônimo único de sofrimento e se considere este espaço/movimento de resistência como uma reinvenção da própria existência coletivamente construída por esses sujeitos.

Os desdobramentos jurídicos da certificação acabam fazendo com que se inicie um processo educativo na comunidade, que passa a olhar para si, percebendo-se como quilombola e iniciando o processo de luta por direitos até então negados. Ao perceber-se como sujeitos de direitos, a luta por uma educação escolar quilombola se constitui como importante instrumento de construção de uma identificação quilombola.

\section{Educação Escolar Quilombola: conceito e diretrizes}

O movimento negro se articulou a partir da República com o intuito de combater os problemas oriundos da discriminação racial existente, sendo que o combate a marginalização do negro implica em propor uma educação que abranja essa população, o que poderia contribuir com a sua inserção social após séculos de escravização e quase impossibilidade de acesso à escola ${ }^{2}$. No caso das questões referentes à aprovação de leis voltadas para a educação das relações étnico-raciais, para as políticas afirmativas ou de reparação, e em especial à educação dos povos quilombolas, foi fundamental a articulação do Movimento Negro Unificado (MNU) e do Movimento Unificado contra a discriminação Racial (MUCDR). Estes grupos lutaram e lutam pela inclusão de conteúdos como História da África nos currículos escolares, além da valorização da estética, religiosidade e outros aspectos da cultura africana e afro-brasileira (DOMINGUES, 2007). 
De acordo com Gomes (2011), nos anos 2000, o movimento negro optou por focar na reivindicação em torno da implantação de políticas afirmativas, tendo na educação uma forma de inserção do negro e promoção da igualdade racial. As primeiras conquistas dessa luta vieram através da implantação do sistema de cotas raciais para ingresso em instituições de ensino superior brasileiras, e, no âmbito da educação básica, com a aprovação da Lei 10.639/2003, que alterou a Lei 9394/96 (Lei de Diretrizes e Bases da Educação Nacional - LDB) indicando a obrigatoriedade dos conteúdos de História e Cultura africana e afro-brasileira nos currículos escolares.

A partir da compreensão da importância e articulação do movimento negro, bem como suas conquistas é que podemos pensar como o contexto brasileiro naquele momento favorecia a retomada de discussões acerca da educação escolar quilombola. Os quilombolas haviam sido lembrados na Constituição Federal de 1988 no artigo 68 das disposições transitórias, mas pouco havia sido feito efetivamente em favor do acesso e permanência dos quilombolas nas escolas básicas. Sobre o contexto da construção das diretrizes curriculares para a Educação Escolar Quilombola, Miranda (2012) afirma que:

A Educação Escolar Quilombola foi implantada a partir de discussões no campo educacional iniciadas na década de 1980 , dotada de forte mobilização e visando à reconstrução da função social das escolas que atendem essas comunidades. Por consequência, os problemas relativos à garantia do acesso à educação pública e da horizontalidade das relações no interior da escola foram expostos; os movimentos sociais identitários passaram a denunciar o papel que a escola apresentava na expressão, repercussão e reprodução do racismo, além das discriminações presentes na organização curricular e nos livros didáticos, entre outros materiais. (MIRANDA, 2012, p. 371).

3 Resolução n ${ }^{\circ}$ 4/2010/CNE/CEB Disponível em: <http://portal.mec gov.br/secretaria-de-regulacao-e-supervisao-da-educacao-superior-seres / 323-secretarias-112877938/ orgaos-vinculados-82187207/12992-diretrizes-para-a-educacao-basica $>$ Acesso em 29/01/2018.
Art. 41. A Educação Escolar Quilombola é desenvolvida em unidades educacionais inscritas em suas terras e cultura, requerendo pedagogia própria em respeito à especificidade étnico-cultural de cada comunidade e formação específica de seu quadro docente, 
4 Parecer $\mathrm{n}^{\circ} 16 \mathrm{CNE} / \mathrm{CEB}$. Disponível em: $<$ https://www.google.com/url?sa=t\&rct $=\mathrm{j} \& \mathrm{q}=\&$ esrc $=\mathrm{s} \&$ source $=$ web\&cd $=1 \& \mathrm{ved}$ =oahUKEwje2r7gzcXbAhUGgJAKHdxq CxUQFggnMAA\&url=http\%3A\%2F\%2Fp ortal.mec.gov.br\%2Fdocman\%2Fjunho2012 - pdf\% 2 F 11091 - p c e b o 16 12\&usg $=$ AOvVaw2jhekbk1rrAyh3E1Ij-3GS $>$ Acesso em 28/01/2018. observados os princípios constitucionais, a base nacional comum e os princípios que orientam a Educação Básica brasileira.

Parágrafo único. Na estruturação e no funcionamento das escolas quilombolas, bem como nas demais, deve ser reconhecida e valorizada a diversidade cultural.

As diretrizes específicas da Educação Escolar Quilombola, foram publicadas como desdobramento do parecer $\mathrm{n}^{\circ} 16 \mathrm{CNE} / \mathrm{CEB}^{4}$, elaborado pela professora Nilma Lino Gomes e aprovado em o6 de junho de 2012.

O parecer orientou-se pelas Diretrizes Curriculares Nacionais Gerais da Educação Básica (2010), pelas deliberações presentes no documento final da Conferência Nacional de Educação (2010), por convenções internacionais como a Convenção 169 da Organização Internacional do Trabalho (OIT) sobre Povos Indígenas e Tribais, pelo artigo 68 das disposições transitórias da Constituição brasileira e por decretos como o $\mathrm{n}^{0}$ 6.040, de 7 de fevereiro de 2007, que instituiu a Política Nacional de Desenvolvimento Sustentável dos Povos e Comunidades Tradicionais, pelo I Seminário Nacional de Educação Quilombola e por audiências públicas e reuniões técnicas organizadas pelo Conselho Nacional de Educação.

É importante evidenciar que a construção das Diretrizes ocorreu com a participação de movimentos sociais, quilombolas ou não, docentes, pesquisadores da área, estudantes e público em geral, pois foi disponibilizado um texto base para discussão e apreciação nas audiências públicas realizadas no Maranhão, Bahia e em Brasília. Nestas audiências, representantes quilombolas não só apreciaram as propostas, como também denunciaram a precariedade da educação escolar que vinha sendo realizada nas comunidades. Os problemas se situavam desde a falta de material, de professores qualificados, merenda e transporte até denúncias de discriminação.

As Diretrizes Curriculares Nacionais da Educação Escolar Quilombola na Educação Básica, Resolução $\mathrm{n}^{\circ} 8$ $\mathrm{CNE} / \mathrm{CEB}$, de 20 de novembro de 2012 estabelecem que a Educação Quilombola se fundamenta a partir da memória coletiva, das línguas reminiscentes, dos marcos civilizatórios, das práticas culturais, das tecnologias e formas de produção do trabalho, da territorialidade, dos acervos e repertórios orais e dos festejos, usos, tradições e demais elementos constitutivos do patrimônio cultural das comunidades quilombolas do país.

Abrangem todas as etapas e modalidades da Educação Básica, estando a Educação Escolar Quilombola destinada a atender comunidades quilombolas rurais e urbanas, sendo ofertada em escolas localizadas nas comunidades reconhecidas como quilombolas ou escolas que recebem alunos quilombolas e tendo como intuito garantir aos estudantes a apropriação dos conhecimentos tradicionais existentes na comunidade, buscando valorizá-los e dar 
continuidade aos mesmos. Quando possível, deve estar em convergência com políticas já existentes e que contemplem os povos do campo e indígenas, levando em consideração suas especificidades.

Nas Diretrizes Curriculares Nacionais para a Educação Escolar Quilombola, o art. $3^{\circ}$ apresenta uma definição de quilombos como:

I - os grupos étnico-raciais definidos por auto-atribuição, com trajetória histórica própria, dotados de relações territoriais específicas, com presunção de ancestralidade negra relacionada com a resistência à opressão histórica;

II - comunidades rurais e urbanas que:

a) lutam historicamente pelo direito à terra $\mathrm{e}$ ao território o qual diz respeito não somente à propriedade da terra, mas a todos os elementos que fazem parte de seus usos, costumes e tradições;

b) possuem os recursos ambientais necessários à sua manutenção e às reminiscências históricas que permitam perpetuar sua memória.

III - comunidades rurais e urbanas que compartilham trajetórias comuns, possuem laços de pertencimento, tradição cultural de valorização dos antepassados calcada numa história identitária comum, entre outros. (MEC. Resolução ${ }^{\circ} 8 \mathrm{CNE} / \mathrm{CEB}$ de 20 de Novembro de 2012).

Tal definição encontra-se em consonância com o exposto no Decreto Presidencial $\mathrm{n}^{\circ}$ 4887/03, marco regulatório do processo de identificação e demarcação dos territórios quilombolas do país, considerando, portanto, a diversidade no que se refere à organização social destes territórios.

De acordo com as Diretrizes Curriculares Nacionais para a Educação Escolar Quilombolas, tanto o Projeto Político-Pedagógico quanto o currículo das escolas quilombolas precisam ser construídos a partir dos valores e interesses das comunidades quilombolas, considerando suas especificidades e visão de mundo. As lideranças quilombolas também precisam ser chamadas à escola para que se façam presentes e opinem nos rumos da escolarização de suas crianças e jovens.

As diretrizes enfatizam ainda a importância de os alunos conhecerem o conceito e história dos quilombos, bem como o protagonismo do Movimento Quilombola e Movimento Negro. O proposto nas Diretrizes nos possibilita compreender a importância e a necessidade de uma educação escolar que assuma uma perspectiva pedagógica intercultural e decolonial, que possibilite a emergência e o fortalecimento de uma identidade étnico-racial e de uma ressignificação da história africana e afro-brasileira.

As Diretrizes também versam sobre aspectos como funções dos entes públicos (Estados, União e Municípios), 
5 Não encontramos a data de publicação do texto. O mesmo se encontra disponível em: <http://www.dhnet.org.br/direitos/militantes/veracandau/textos.htm > Acesso em 12/06/2018. a organização da Educação Escolar Quilombola, suas etapas e modalidades, nucleação e transporte escolar, gestão das escolas quilombolas, avaliação e formação inicial e continuada dos professores que atuam ou atuarão nas comunidades.

Contudo, como indica Souza (2015), as Diretrizes por si só não garantirão a transformação da realidade das escolas quilombolas, mas demarcam politica e pedagogicamente uma conquista do movimento negro que se materializa como documento norteador que aborda especificidades das escolas quilombolas a serem observadas para que se reduzam as disparidades escolares às quais as comunidades quilombolas estão sendo submetidas.

É importante ressaltar ainda que as Diretrizes foram formuladas a partir de um entendimento consensual de que a escola é um locus imprescindível na ressignificação da identidade étnica das crianças e jovens quilombolas. Por isso há uma articulação entre a Educação Quilombola, entendida como composta por valores e percepções locais e a educação formal. A Escola deve estar com seu discurso alinhado às demandas locais, evitando que se reproduzam discursos que sejam opostos ao defendido pelo movimento quilombola, por exemplo.

O protagonismo dos quilombolas na construção do currículo é importante para que o mesmo não seja um elemento alheio à realidade das comunidades. Trata-se do que Arroyo (2014, p. 27) define como colocar "os oprimidos como sujeitos de sua educação, de construção de saberes, conhecimentos, valores e cultura”. Esta conexão entre a educação formal (Educação Escolar Quilombola) e a educação informal (Educação Quilombola) não é uma tarefa simples, pois em alguns momentos os conhecimentos podem se mostrar divergentes, sendo um desafio a ser superado em favor de uma escolarização de qualidade para os alunos quilombolas.

\section{EducaçãoEscolarQuilombola,decolonialidade e interculturalidade}

Diante dos objetivos e princípios da Educação Escolar Quilombola, percebemos ser essencial que haja uma ressignificação da trajetória de africanos e seus descendentes aqui no Brasil, superando a situação de marginalização, vitimização e invisibilidade existente ainda nos recursos didáticos levados para as escolas brasileiras. Assim, julgamos pertinente para a consecução desses objetivos e princípios o alinhamento com uma perspectiva pedagógica intercultural e decolonial.

Candau (s/d) ${ }^{5}$ esclarece que a perspectiva intercultural surgiu recentemente motivada, além de razões pedagógicas, por aspectos sociais, políticos, ideológicos e estruturais. Teria surgido nos Estados Unidos da América - EUA, há cerca de trinta anos e estaria ligada ao surgimento de movimentos reivindicatórios liderados por minorias 
étnico-culturais. Assim como nos EUA, estes movimentos reivindicatórios se espalharam e estes possuíam em sua pauta de luta demandas sociais, culturais e educativas, visando, dentre outros interesses, a consideração de suas línguas e culturas pela educação escolar.

No que se refere à América Latina, Candau nos indica que a perspectiva intercultural surgiu a partir das populações indígenas, tendo nos movimentos de educação popular um importante instrumento de promoção de processos educativos a partir das culturas destes grupos. A autora conclui que a preocupação com uma educação que considere a diversidade cultural na América Latina é anterior ao movimento iniciado nos EUA.

A autora ainda reconhece, e nós concordamos, que nos espaços escolares a cultura dominante é a que corresponde à visão de determinados grupos sociais, tendo pouco destaque a cultura popular e as contribuições de grupos como mulheres e demais grupos marginalizados. A cultura escolar encontra-se engessada, buscando padronizações. Reconhecemos a existência de uma sociedade multicultural mas, no entanto, isto não significa necessariamente que estamos em pleno desenvolvimento de uma dinâmica intercultural.

Candau e Russo (2010) indicam que há vasta produção sobre o tema nos países colonizados pelos espanhóis, sobretudo na América Andina. No caso do Brasil, as autoras indicam que a produção teve aumento, sobretudo após a Constituição de 1988, quando as especificidades de comunidades indígenas e quilombolas passaram a ser reconhecidas.

A interculturalidade pressupõe a interrelação entre diferentes culturas, ou seja, demanda uma reciprocidade, um intercâmbio. Meinerz, Antunes e Bergamashi (2015) utilizam os povos ameríndios como exemplos daquilo que se entende por interculturalidade. As autoras compartilham os raciocínios de Canclini (2007) e Levi-Strauss (1993) para concluir que os povos indígenas são os mais preparados para um diálogo intercultural, que é entendido como não apenas uma disposição ao diálogo, como é comumente entendido, mas também como a disposição de saberes e conhecimentos do outro para qualificar este diálogo. Obviamente que este diálogo não ocorre de forma totalmente pacífica, sendo a interculturalidade um princípio pautado na confrontação.

Para que o diálogo intercultural ocorra, é necessário que haja abertura para o outro: "buscar no outro uma complementaridade" (MEINERZ et al., 2015, p. 93). Nesse sentido, as autoras mostram que os povos indígenas utilizam a educação escolar (imposta pela colonização e existente nos séculos seguintes) como forma de interação com os modos de vida próprios e também com os modos de vida, ciência e língua de grupos não indígenas, estabelecendo assim 
um diálogo mais igual entre as sociedades. Tal perspectiva também encontra viabilidade no que se refere à Educação Escolar Quilombola.

Ao passo que os indígenas empreendem este esforço dialógico, as escolas têm como função se esforçar para conhecer esses povos, sua história e cultura, superando visões estereotipadas ou a invisibilidade a que foram submetidos. Assim, a presença indígena nas instituições escolares (básicas e superiores) nada mais é que a escolha deste ambiente como um aliado para sua afirmação étnica e para o diálogo com os outros grupos. Dentro da pauta de luta indígena está, além do direito à terra, ou a saúde, a preocupação de fazer com que nas escolas não indígenas se cheguem informações mais condizentes acerca de sua história, pautada em conhecimentos que os respeitem e valorizem, mudando concepções preconceituosas ou discriminatórias.

Para Candau:

[...] a interculturalidade orienta processos que têm por base o reconhecimento do direito à diversidade e a luta contra todas as formas de discriminação e desigualdade social e tentam promover relações dialógicas e igualitárias entre pessoas e grupos que pertencem a universos culturais diferentes. Neste sentido, trata-se de um processo permanente, sempre inacabado, marcado por uma deliberada intenção de promover uma relação dialógica e democrática entre as culturas e os grupos involucrados e não unicamente uma coexistência pacífica num mesmo território. (CANDAU, s/d. p. 4).

Assim como os indígenas, os povos negros, e consequentemente, os quilombolas, não encontraram na educação escolar o devido espaço e enfrentam até hoje dificuldades. Estes povos estiveram em condição de invisibilidade e ausência de cidadania mesmo após a abolição da escravatura e vem, ao longo do tempo, lutado por direitos e pelo reconhecimento de sua cultura. Para Candau e Russo (2010):

A situação dos afro-descentes na maior parte do continente tem sido configurada por processos de violência e exclusão física, social e simbólica. No entanto, em diferentes nações, foram muitas as lutas de grupos afro-descendentes por condições de vida dignas e combate à discriminação e ao racismo. Esses grupos têm se caracterizado pela resistência e por suas lutas contra o racismo em suas diferentes manifestações, assim como pela afirmação de direitos e plenitude de cidadania, o que supõe reconhecimento de suas identidades culturais. (CANDAU e RUSSO, 2010, p. 8).

Os autores reconhecem que a produção acerca da contribuição dos movimentos negros com relação à 
dinâmica intercultural ainda é menor quando comparada à produção dos grupos indígenas. Enfatizam as denúncias feitas com relação ao racismo e práticas discriminatórias em meio a uma dinâmica de escolarização onde ainda predomina a ideia da democracia racial, que acaba por mascarar a hierarquização cultural difundida pelo colonizador. A difusão do mito da democracia racial faz com que se pense que nossa sociedade se formou a partir de grupos diferentes que se integraram de uma forma cordial, o que ajuda na perpetuação de estereótipos e no não reconhecimento do racismo nosso de cada dia.

Para as autoras, os movimentos negros têm produzido diferentes leituras acerca do processo histórico vivenciado e demandam por reparações com relação aos danos sofridos por africanos e afrodescendentes em decorrência do sistema escravista e das políticas de branqueamento e exclusão socioeconômica e cultural dos negros da sociedade no pós-abolição.

Como fruto dessas releituras e da luta do movimento negro no Brasil, no âmbito educacional, podemos evidenciar as políticas afirmativas de acesso e permanência dos negros nos diferentes sistemas educacionais, a obrigatoriedade, nos currículos escolares e materiais didáticos da inclusão de conteúdos referentes ao estudo das culturas negras e seus processos históricos de resistência vividos, enfatizando de forma positiva a contribuição destes para a sociedade brasileira. Esse tipo de ação vem do questionamento dos padrões eurocêntricos em uso e da defesa do reconhecimento e valorização das diferenças culturais.

Podemos referenciar ainda a luta dos movimentos organizados dentro das comunidades quilombolas em prol de uma educação escolar específica e diferenciada que aborde a história, cultura e saberes tradicionais de suas comunidades. Dentro da perspectiva intercultural estão os críticos e propositores de uma pedagogia decolonial. Deste grupo fazem parte intelectuais como Walsh, Quijano e Mignolo. Tal perspectiva parte do pressuposto de que os países latinos americanos alcançaram sua independência política, no entanto, ainda se encontram atrelados a padrões - em termos de estruturas, instituições e mentalidade - coloniais.

Para Campos e Souza (2015), durante o período da colonização, predominava o paradigma da modernidade como eixo de compreensão da história, ciência, linguagem, religião, economia, educação e outros aspectos que compõe as sociedades partindo de um centro, que no caso era a sociedade europeia. Dentro desse paradigma moderno temos o sistema colonial enquanto regime político-administrativo e militar instaurado nas colônias e objetivando a transferência de riquezas das colônias para as metrópoles. Como polo central do colonialismo, o padrão europeu acaba por se estabelecer e instituir uma hierarquização entre as culturas.

Os autores que propõe uma pedagogia crítica decolonial, ao analisar o paradigma da modernidade e a colonialidade, estabelecem categorias como colonialidade do poder, 
do saber e do ser. Sobre elas, Candau e Russo (2010) nos esclarecem que:

A colonialidade do poder refere-se aos padrões de poder baseados em uma hierarquia (racial, sexual) e na formação e distribuição de identidades (brancos, mestiços, índios, negros). Quanto à colonialidade do saber, refere-se ao caráter eurocêntrico e ocidental como única possibilidade de se construir um conhecimento considerado científico e universal, negando-se outras lógicas de compreensão do mundo e produção de conhecimento, consideradas ingênuas ou pouco consistentes. A colonialidade do ser supõe a inferiorização e subalternização de determinados grupos sociais, particularmente os indígenas e negros. (CANDAU e RUSSO, 2010, p. 15)

Então, para este grupo de autores, uma educação intercultural deve servir para questionar os padrões coloniais presentes na sociedade e na própria educação, escancarando aspectos como o racismo, por exemplo, e servindo para defender o reconhecimento dos saberes e práticas em condição dialógica. A decolonialidade proposta por estes intelectuais se refere à superação das categorias acima referenciadas mediante críticas ao eurocentrismo e o reconhecimento e valorização da diversidade cultural.

No que se refere à colonialidade/decolonialidade e a questão das comunidades quilombolas, Campos e Souza (2015) indicam que os quilombos eram redutos contra o colonialismo e a colonialidade que inferiorizavam o negro já desde a sua captura e invisibilização identitária (todos eram negros, não havia mais etnias, culturas e mesmo nomes). Os negros foram despojados de sua cultura e identidade e diante dessa realidade resistiram e lutaram durante todo o período colonial. O fim do sistema colonial não representou o fim do colonialismo e da colonialidade e as lutas dos negros se desdobraram em outras demandas, como, por exemplo, uma educação específica para as comunidades quilombolas, a própria reivindicação territorial ou as políticas afirmativas. Apesar do fim da colonização e da abolição da escravatura, a colonialidade ainda permanece arraigada em nossa sociedade.

No que se refere às políticas educacionais que foram alvo de reivindicação por parte dos movimentos negro e quilombola podemos citar como conquistas a aprovação da Lei $\mathrm{n}^{\circ}$ 10.639/o3 e da Resolução ${ }^{\circ}$ 08/2012 do CNE/ CEB. Estas foram conquistas importantes no sentido de promover a ampliação do foco dos currículos escolares valorizando a diversidade de culturas, raças ou classes sociais existentes no país. A África, os africanos e os afro-brasileiros passam a ser vistos sob uma perspectiva positiva. Para Campos e Souza (2015), não se trata de substituir o eurocentrismo pelo afrocentrismo, mas de estabelecer uma 
prática educativa decolonial/intercultural fundamentada na horizontalidade e respeito mútuo, superando a pedagogia pautada num padrão hierarquizante.

Campos e Souza (2015) mencionam o pensamento de Walsh (2009) e Arroyo (2013) para quem a pedagogia colonial pautada no padrão da modernidade nega a história, a ancestralidade e a cultura de grupos como os quilombolas, tornando-os sujeitos invisibilizados por estar fora do padrão colonial de ser/saber. A pedagogia decolonial é construída a partir das pessoas invisibilizadas, valorizando seus saberes ancestrais, sua corporeidade, identidades e histórias.

Concordamos com Campos e Souza (2015) quando concluem que o movimento quilombola comporta em sua essência uma resistência à subalternização imposta pela colonialidade, e esta luta se projeta em vários setores como o territorial e o educacional. Os princípios da interculturalidade e da pedagogia decolonial estão presentes nas Diretrizes da Educação Escolar Quilombola na medida em que buscam promover uma visão identitária positiva acerca do negro e do quilombola buscando o diálogo com o diferente em condição de igualdade e respeito.

Partindo desse aporte teórico, entendemos que a Educação Escolar Quilombola traz em sua essência o enaltecimento da chamada Educação Quilombola dentro do ambiente escolar. Trata-se de valorizar os sujeitos, os lugares, os seus modos de fazer, agir, sentir e se relacionar. Implica trazer a sabedoria popular para dentro da escola, de forma que os discentes identifiquem que o conhecimento produzido por seu grupo no dia-a-dia é válido e representa uma resistência contra séculos de opressão a que os africanos e seus descendentes foram submetidos. Possibilitar a emergência da memória coletiva, presente na corporeidade, na fala, nas rezas, nas festas, nas lutas, para a sala de aula torna-se fundamental no processo de identificação dos sujeitos com sua ancestralidade.

Por meio de uma abordagem pedagógica crítica (decolonial) os alunos poderão, ao se sentir parte de um grupo oprimido socialmente, passar a engrossar as fileiras de resistência e lutar por seus direitos.

Para Carril (2017), o reconhecimento dos quilombos pela via legal a partir da Constituição de 1988 é um marco histórico no sentido de tornar visíveis as diferenças étnicas existentes na sociedade brasileira, porém, o mito da democracia racial introjetado em nossa sociedade acabou contribuindo para esconder a escravidão e para o menosprezo da cultura africana e afro-brasileira o que, por sua vez, causa interferência na identificação dos indivíduos afrodescendentes.

A Educação Escolar Quilombola é um elemento importante no que concerne à ampliação dos direitos dos grupos afrodescendentes. No entanto, Carril (2017) alerta que para que haja efetivamente o preconizado nas Diretrizes, é preciso que haja alteração na cultura escolar, que não 
abrange a diversidade. Nesse sentido, a perspectiva pedagógica decolonial auxilia nesse processo de desconstrução de estereótipos negativos com relação à trajetória do negro no Brasil, convergindo para um processo de identificação positiva de crianças e jovens estudantes.

\section{Referências}

ARROYO, Miguel G. Outros sujeitos, outras pedagogias. Petrópolis: Vozes, 2014.

BASTOS, Priscila da Cunha. Entre o quilombo e a cidade: trajetórias de individuação de jovens mulheres negras. Programa de Pós-Graduação em Educação. Dissertação de Mestrado: UFF, Niterói, 2009.

BRASIL. Conselho Nacional de Educação. Parecer CNE/ CEB n. 13/2012 de 10 de Maio de 2012. Diretrizes Curriculares Nacionais para a Educação Escolar Indígena. Diário Oficial da União, Brasília, DF, 15 jul. 2012. P. 18.

BRASIL. Conselho Nacional de Educação. Parecer CNE/ CEB n. 16/2012 de 05 de Junho de 2012. Diretrizes Curriculares Nacionais para a Educação Escolar Quilombola. Diário Oficial da União, Brasília, DF, 20 nov. 2012. P. 8.

BRASIL. Conselho Nacional de Educação. Parecer CNE/CP n. 003/2004 de 10 de Março de 2004. Diretrizes curriculares nacionais para a educação das relações étnico-raciais e para o ensino de História e Cultura Afro-brasileira e Africana. Diário Oficial da União, Brasília, DF, 19 maio 2004.

BRASIL. Ministério da Educação. Lei n. 10.639 de o9 de Janeiro de 2003. Altera a Lei no 9.394, de 20 de dezembro de 1996, que estabelece as diretrizes e bases da educação nacional, para incluir no currículo oficial da Rede de Ensino a obrigatoriedade da temática "História e Cultura Afro-Brasileira”, e dá outras providências. Diário Oficial da União, Brasília, DF, 10 jan. 2003. P. 1.

BRASIL. Ministério da Educação. Lei n. 11.645 de 10 de Março de 2008. Altera a Lei 9.394, de 20 de dezembro de 1996, modificada pela Lei 10.639, de 9 de janeiro de 2003, que estabelece as diretrizes e bases da educação nacional, para incluir no currículo oficial da rede de ensino a obrigatoriedade da temática "História e Cultura Afro-Brasileira e Indígena”. Diário Oficial da União, Brasília, DF, 11 mar. 2008. P. 1.

CAMPOS, Louise Rodrigues.; SOUZA, Sulivan Ferreira de. Educação Quilombola e Decolonialidade: Um Diálogo Intercultural. IN: XII Congresso Nacional de Educação. 2015. 
CANCLINI, Néstor García. Culturas Híbridas: estratégias para entrar e sair da modernidade. Tradução de Ana Regina Lessa e Heloísa Pezza Cintrão. São Paulo: EDUSP, 1997.

CANDAU, Vera Maria F. Interculturalidade e Educação Escolar. Disponível em: <http://www.dhnet.org.br/direitos/militantes/veracandau/textos.htm $>$ Acesso em 12/06/2018.

CANDAU, Vera Maria F. Concepção de Educação Intercultural. Rio de Janeiro: Editora PUC-Rio, 2014. (Documento de trabalho).

CANDAU, Vera Maria F. e RUSSO, Kelly. Interculturalidade e Educação na América Latina: uma construção plural, original e complexa. In: Rev. Diálogo Educ., Curitiba, v. 10, n. 29, p. 151-169, jan./abr. 2010.

CASTELlS, M. O poder da identidade. Tradução de Klauss Brandini Gerhardt. 5. ed. São Paulo: Paz e Terra, 2006. (A era da informação: economia, sociedade e cultura) v. 2.

CARRIL, Lourdes de Fátima Bezerra. Os desafios da educação quilombola no Brasil: o território como texto e contexto. IN: Revista Brasileira de Educação. v. 22, n. 69 - abr-jun, 2017, p. 539-564.

DOMINGUES, Petrônio. Movimento negro brasileiro: alguns apontamentos históricos. IN: Tempo, Niterói, v. 12, n. 23, 2007, p. $100-122$.

FLEURI, Reinaldo Matias. Educação Intercultutal: decolonializar o poder e o saber, o ser e o viver. IN: Visão Global: Joaçaba, v.15, n. 1-2, p. 7-22, jan/dez, 2012.

GOMES, Nilma Lino. A mulher negra que vi de perto. Belo Horizonte: Mazza edições, 1995.

GOMES, Nilma Lino. O movimento negro no Brasil: ausências, emergências e a produção dos saberes. Política \& Sociedade, v. 10, n. 18, 2011.

LÉVI-STRAUSS, Claude. Histórias de Lince. Tradução Beatriz Perrone-Moisés. São Paulo: Companhia das Letras, 1993 .

LUCINI, Marizete. Memória e história na formação da identidade Sem Terra no Assentamento Conquista na Fronteira. Tese de Doutorado. 238 fls. Faculdade de Educação UNICAMP, 2007.

MEC. Resolução CNE/CEB n. 8 de 20 de Novembro de 2012. Diretrizes Curriculares Nacionais para a Educação Escolar Quilombola. 
MEINERZ, Carla B., ANTUNES, Cláudia, BERGAMASCHI, Maria Aparecida. Interculturalidade e Educação das Relações Étnico-Raciais: reflexões sobre a aplicação da Lei 11.645/o8 No Rio Grande do Sul. Revista Periferia, v. 7 , n. 1, jan/jun.2015. Disponível em: <http:// www.e-publicacoes.uerj.br/index.php/periferia/article/ view/21972/15951 > Acesso em 29.07.2018.

MIRANDA, Shirley Aparecida. Educação escolar quilombola em Minas Gerais: entre ausências e emergências. IN: Revista Brasileira de Educação, Rio de Janeiro, v. 17, n. 50, maio/ago. 2012. p, 369-383.

MOURA, Glória. Aprendizado nas comunidades quilombolas: currículo invisível. In: BRAGA, Maria Lúcia de Santana ; SOUZA, Edileuza Penha de ; PINTO, Ana Flávia Magalhães (Org.). Dimensões da inclusão no Ensino Médio: mercado de trabalho, religiosidade e educação quilombola. Brasília: Ministério da Educação, Secretaria de Educação Continuada, Alfabetização e Diversidade, 2006. p. 263273. (Coleção educação para todos, v. 9).

SIMAS, Tanussa. Quadra: um estudo sobre descendência negra e a construção da identidade quilombola. IN: $3^{\mathbf{0}}$ Prêmio Territórios Quilombolas / Leite, Renata, Dantas, Isolda, Cerqueira, Edmilton [org.] - Brasília: Ministério do Desenvolvimento Agrário, 2012. p. 363-384.

SILVA, Júlia Bueno de M. História, Ensino e Identidade nas Escolas Quilombolas. IN: ANPUH - XXV Simpósio Nacional de História: Fortaleza, 2009.

SOUZA, Shirley Pimentel de. Educação Escolar Quilombola: As pedagogias quilombolas na construção curricular. Dissertação de Mestrado, Faculdade de Educação, Universidade Federal da Bahia, 2015.

SOUZA, Márcia Lucia Anacleto de. Educação e identidade no Quilombo Brotas. Universidade Estadual de Campinas - Faculdade de Educação (Dissertação de Mestrado). Campinas, 2009.

WALSH, Catherine. Interculturalidade crítica e pedagogia Decolonial: in-surgir, re-existir e re-viver. In: CANDAU, Vera (Org.). Educação Intercultural na América Latina: entre concepções, tensões e propostas. Rio de Janeiro: 07 Letras, 2009. 